Izuho Hatada - Azusa Kato • Sumiyo Morita

Yayoi Obata · Kayuri Nagaoka - Akira Sakurada

Masami Sato • Akira Horii • Atsumi Tsujimoto

Kenichi Matsubara

\title{
A microarray-based method for detecting methylated loci
}

\begin{abstract}
CpG}$ island DNA methylation plays an important role in regulating gene expression in development and carcinogenesis. We developed a new microarray-based method called methylation amplification DNA chip (MAD) for detecting differences in methylation. In this method, only methylated $\mathrm{CpG}$ islands from the two samples that we wanted to compare were amplified and used for hybridization. The resource material for the microarray was derived from the methylated DNA library of the sample in which we wanted to detect hypermethylation. Choosing the methylated DNA library as the resource material of the microarray increased the percentage of DNA fragments derived from hypermethylated loci on the microarray.
\end{abstract}

Key words DNA methylation - DNA chip · Microarray · CpG island $\cdot$ Hypermethylation

\section{Introduction}

The great majority of cytosine residues of $\mathrm{CpG}$ dinucleotides are methylated in the human genome, but some

I. Hatada $(\bowtie) \cdot$ S. Morita $\cdot$ Y. Obata

Gene Research Center, Gunma University, 3-39-22 Showa-machi,

Maebashi 371-8511, Japan

Tel. +81-27-220-8057; Fax +81-27-220-8059

e-mail: ihatada@showa.gunma-u.ac.jp

A. Kato $\cdot$ A. Tsujimoto $\cdot$ K. Matsubara

DNA Chip Research Inc., Yokohama, Japan

K. Nagaoka $\cdot$ A. Sakurada $\cdot$ M. Sato

Department of Thoracic Surgery, Institute of Development, Aging and Cancer, Tohoku University, Sendai, Japan

A. Horii

Department of Molecular Pathology, Tohoku University School of Medicine, Sendai, Japan

K. Matsubara

Taisho Laboratory of Functional Genomics, Nara Institute of

Science and Technology, Ikoma, Japan remain unmethylated in specific GC-rich areas, called $\mathrm{CpG}$ islands (Antequera et al. 1990). These small stretches of DNA sequences are located in the promoter and first exon regions of $60 \%$ of human genes ( $\mathrm{Ng}$ and Bird 1999). DNA methylation of cytosine within $5^{\prime} \mathrm{CpG}$ islands is associated with loss of gene expression and plays a role in regulating gene expression during development. This epigenetic event is frequently associated with the transcriptional silencing of imprinted genes, some repetitive elements, and genes on the inactive X chromosome ( $\mathrm{Li}$ et al. 1993; Singer-Sam and Riggs 1993). In neoplastic cells, the CpG islands of some tumor suppressor genes become aberrantly methylated (Uones 1996; Baylin et al. 1997).

Several techniques, such as restriction landmark genomic scanning (RLGS) and a representational difference analysis (RDA)-based method, have been developed to detect differences in methylation when searching for imprinted genes and aberrantly methylated genes in cancer cells (Hatada et al. 1993; Toyota et al. 1999). Although these techniques are very powerful for detecting methylation differences, the number of $\mathrm{CpG}$ islands cloned by using RLGS is limited, and the methylation difference of each gene is not detected by RDA. Very recently, a microarray-based technique for the detection of differences in methylation has been developed (Yan et al. 2001). In that method, both non- $\mathrm{CpG}$ sequences and $\mathrm{CpG}$ islands resistant to cleavage by the methylation-sensitive restriction enzyme $B s t \mathrm{UI}$ from two samples are amplified and cohybridized to the microarray panel. However, amplification of non- $\mathrm{CpG}$ islands can reduce the signal intensities derived from $\mathrm{CpG}$ islands. Moreover, when using that method, an enormous number of clones must be fixed in microarrays to detect the hypermethylated loci. Here, we describe a new method called methylation amplification DNA chip (MAD). In this method, only CpG islands, which are important for transcriptional regulation, are amplified. A microarray was made from the methylated clones of the sample in which we wanted to detect hypermethylation. This increased the percentage of DNA fragments derived from hypermethylated loci on the microarray (Fig. 1A). 
Fig. 1. A Schematic flowchart for the Methylation Amplification DNA chip (MAD) method. B Representative results of MAD applied to newborn mouse whole body and embryonic stem (ES) cells. Methylated $\mathrm{CpG}$ islands of newborn mouse whole body and ES cells were labeled with $\mathrm{Cy} 3$ and $\mathrm{Cy} 5$, respectively, and cohybridized to a microarray slide containing M1M8 in triplicate. The hybridization output is the measured intensities of the two fluorescence reporters false-colored with red (newborn mouse whole body) and green (ES cells). M2 (arrows) has a stronger signal intensity $(\mathrm{Cy} 3: \mathrm{Cy} 5=2.8)$ for Cy3 (newborn mouse), which indicates hypermethylation in newborn mouse compared with ES cells. C Southern blot analysis of newborn mouse whole body $(N)$ and ES cells $(E)$ using M1-M8 as probes. Digests were carried out by using the methylation-sensitive restriction enzyme $S m a I$. Methylated $(M)$ and unmethylated $(U)$ fragments are indicated. ME, methylated SmaI sites; PCR, polymerase chain reaction

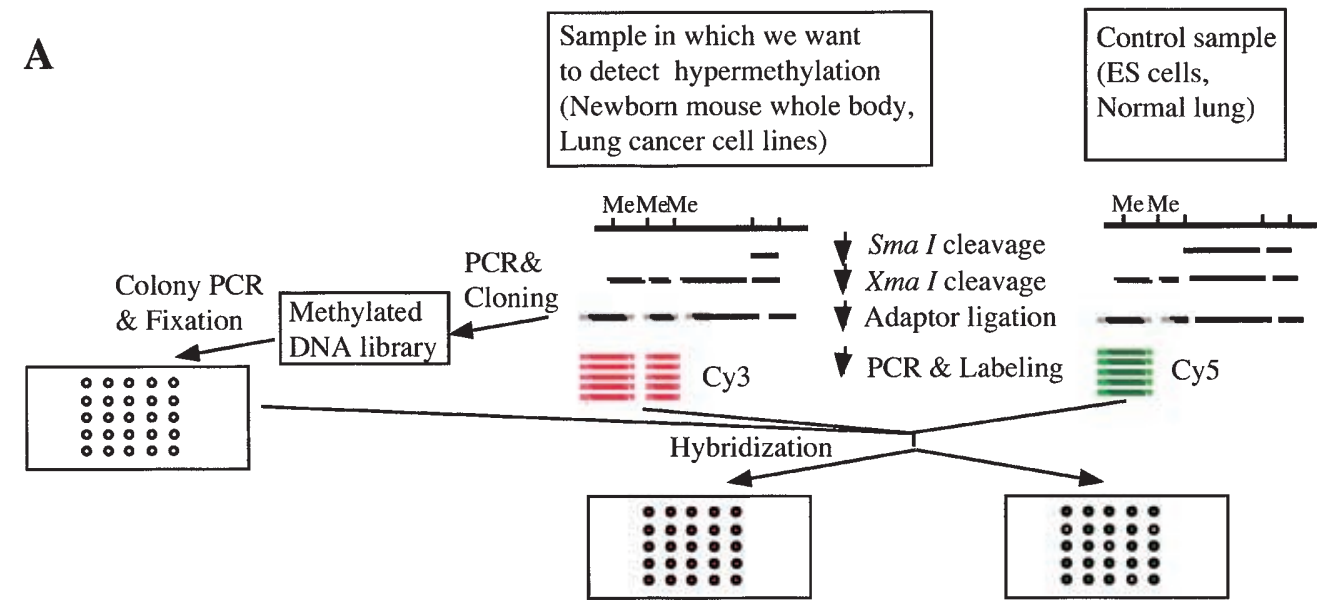

Me: Methylated Sma I sites

B Cy3(Newborn mouse)

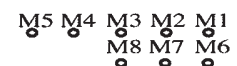

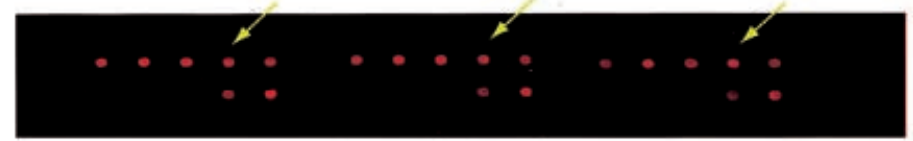

Cy5(ES cells)
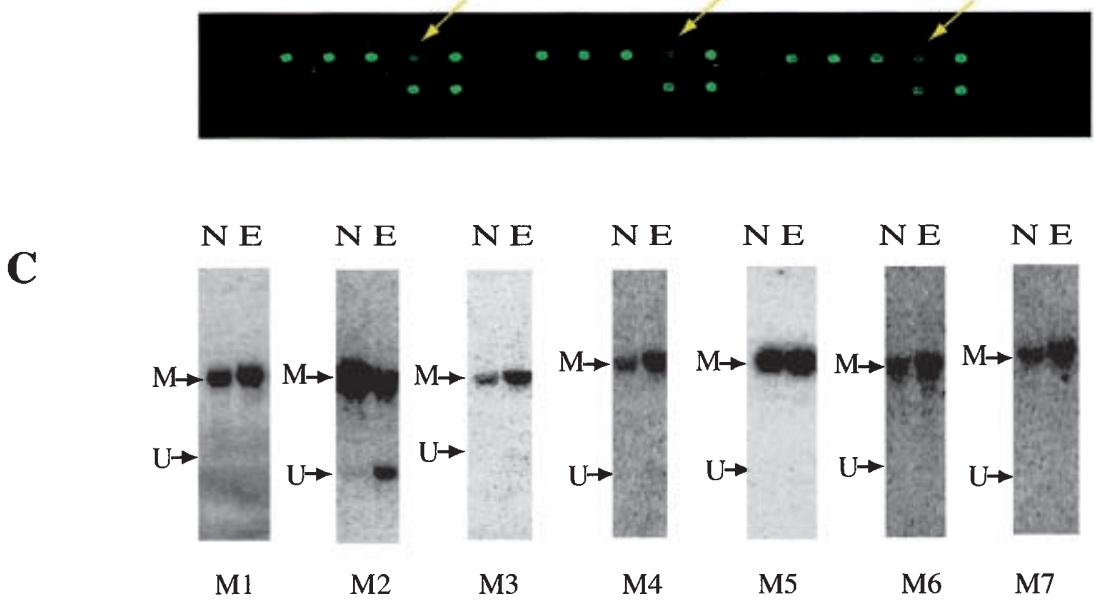

\section{Materials and methods}

MAD

The procedure is illustrated in Fig. 1A. One microgram of genomic DNA was digested with 40 units of SmaI overnight. The DNA was further digested with 50 units of $\mathrm{XmaI}$ for $8 \mathrm{~h}$. The digests were extracted with phenol:chloroform and precipitated with ethanol. The adaptor were prepared by annealing the two oligonucleotides AGCACTCTCCAG CCTCTCACCGAC and CCGGGTCGGTGA. Approximately $0.5 \mu \mathrm{g}$ of DNA was ligated to $0.8 \mathrm{pmol}$ of the adaptor by using T4 DNA ligase. Polymerase chain reaction (PCR) was performed by using $0.1 \mu \mathrm{g}$ of each ligation mix as a template in a $50-\mu \mathrm{l}$ volume containing $50 \mathrm{pmol}$ of the primer AGCACTCTCCAGCCTCTCACCGAC, 1.25 units of Taq DNA polymerase, $10 \mathrm{mM}$ Tris $\mathrm{HCl}(\mathrm{pH} 8.3), 50 \mathrm{mM} \mathrm{KCl}$, $1.5 \mathrm{mM} \mathrm{MgCl} 2,0.2 \mu \mathrm{M} \mathrm{dNTP}$, and $15 \%$ dimethylsulfoxide (DMSO). The reaction mixture was incubated for $5 \mathrm{~min}$ at $72^{\circ} \mathrm{C}$ and for $3 \mathrm{~min}$ at $94^{\circ} \mathrm{C}$ and subjected to 25 cycles of amplification consisting of $10 \mathrm{~s}$ denaturation at $94^{\circ} \mathrm{C}, 30 \mathrm{~s}$ annealing at $70^{\circ} \mathrm{C}$, and $2.5 \mathrm{~min}$ extension at $72^{\circ} \mathrm{C}$. The final extension was lengthened to $9.5 \mathrm{~min}$. PCR products were purified by using a QIAquick PCR Purification Kit (QIAGEN, Valencia, CA, USA). One hundred monograms of PCR product was labeled as described (Pollack et al. 1999) by using Cy3-dCTP or Cy5-dCTP.

To make resource material for the microarrays, the PCR products were digested with XmaI and ligated to XmaI- 
digested pBluescript. After transformation, each colony was amplified by PCR by using primers GATATCGAA TTCCTGCAGCC and CGCTCTAGAACTAGTGGATC in the presence of 1.25 units of Taq DNA polymerase, $10 \mathrm{mM}$ Tris $\mathrm{HCl}(\mathrm{pH} 8.3), 50 \mathrm{mM} \mathrm{KCl}, 1.5 \mathrm{mM} \mathrm{MgCl}$, $0.2 \mu \mathrm{M}$ dNTP, and $15 \%$ DMSO. The reaction mixture was incubated for $5 \mathrm{~min}$ at $94^{\circ} \mathrm{C}$ and subjected to 40 cycles of amplification consisting of $10 \mathrm{~s}$ denaturation at $94^{\circ} \mathrm{C}, 30 \mathrm{~s}$ annealing at $60^{\circ} \mathrm{C}$, and $1 \mathrm{~min}$ extension at $72^{\circ} \mathrm{C}$. Amplified DNA fragments were fixed on poly-L-lysine-coated microscope slides as described by Schena et al. (1995) by using the SPBIO-2000 (Hitachi Software Engineering, Yokohama, Japan) arrayer. Labeled DNA was cohybridzed to the microarray and scanned by using the Scan Array4000 (GSI Lumonics, Tokyo, Japan) arrayer. Global mean normalization was used to normalize $\mathrm{Cy} 3$ and $\mathrm{Cy} 5$ signals (Roberts et al. 2000).

\section{Methylation-specific PCR}

Genomic DNA was treated with sodium bisulfite by using a CpGenome DNA Modification Kit (Intergen, Norcross, GA, USA) and subjected to methylation-specific PCR (MSP). The MSP primer sequences that specifically recognized the methylated MIN26 sequence were TTTTAGAT TAACGAGTTGGGCGAC and CGACTACATCAAAA ACACGCCGA and those that recognized the unmethylated MIN26 sequence were TTGTGGAGTGATATA TTGGAAGTG and CATCAAAAACACACCAACCAA TATCA.

\section{Results and discussion}

Toyota et al. (1999) described a method called methylated $\mathrm{CpG}$ island amplification (MCA) for amplifying only methylated $\mathrm{CpG}$ islands. We utilized this method to prepare both probes and targets for hybridization. About $70 \%-80 \%$ of $\mathrm{CpG}$ islands contain at least two closely spaced $(<1 \mathrm{~kb})$ SmaI sites (CCCGGG) (Toyota et al. 1999). Only those SmaI sites within these short distances can be amplified by using the MCA method, ensuring representation of the most CpG-rich sequences. The DNA is cleaved with a methylation-sensitive restriction enzyme SmaI, which makes blunt ends, followed by cleavage with the XmaI, which is a methylation-insensitive isoschizomer of $S m a \mathrm{I}$ and makes 5' protruding ends. Adaptors specific for XmaIcleavage ends are ligated, and PCR amplification in the presence of $15 \%$ DMSO is performed by using primers complementary to these adaptors. As a result, only DNA fragments between two methylated and closely spaced SmaI/XmaI sites can be amplified. Methylated DNAs from the two samples that we wanted to compare were amplified by MCA and labeled as described by Pollack et al. (1999) by using Cy3-dCTP and Cy5-dCTP, respectively, and used for cohybridization. For resource material for making the microarrays, we constructed a methylated DNA library from the sample in which we wanted to detect hypermethylation. DNA from the samples in which we wanted to detect hypermethylation was amplified by MCA. Amplified DNA fragments were cleaved with $X m a \mathrm{I}$ and cloned into XmaI sites of pBluescript. After transformation, each colony was amplified by PCR by using the primers GATATCGAATTCCTGCAGCC and CGCTCTAGA ACTAGTGGATC in the presence of $15 \%$ DMSO. Amplified DNA fragments were fixed on poly-L-lysinecoated microscope slides as described by Schena et al. (1995) by using the SPBIO-2000 (Hitachi Software Engineering) arrayer. Labeled DNA was cohybridzed to the microarray and scanned by using the Scan Array4000 (GSI Lumonics) arrayer. Global mean normalization was used to normalize Cy3 and Cy5 signals (Roberts et al. 2000).

For a model experiment, DNAs from newborn mouse whole body (Cy3) and embryonic stem (ES) cells (Cy5) were analyzed by using MAD. The resource material for preparing the microarray was derived from a methylated DNA library of newborn mouse (M1-M7: Accession numbers AB083485-AB083491) and human control DNA (M8). Each DNA was spotted in triplicate. The spot intensity derived from each DNA was reproducible (Fig. 1B). The signal intensity of the M1-M7 spots is strong, whereas the humanderived M8 spot gives no signal. Among seven spots, the signal intensity of M2 was stronger $(\mathrm{Cy} 3: \mathrm{Cy} 5=2.8)$ for $\mathrm{Cy} 3$ (newborn mouse), which indicates hypermethylation in newborn mouse compared with ES cells. These results were confirmed by Southern blot analysis with SmaI (Fig. 1C).

We applied MAD to three lung cancer cell lines (EBC-1, 1-87, and LK79). The resource material for preparing the microarray was derived from the methylated DNA library (H1-H192) of four cancer cell lines (EBC-1, 1-87, PCI19, and PK1; the latter two are pancreatic cancer cell lines) and hypermethylated DNA fragments (MINT1-MINT32) in a colon cancer cell line Caco2 (Toyota et al. 1999). The methylated DNAs from the cancer cell lines were labeled with $\mathrm{Cy} 3$, and DNA from normal lung was labeled with Cy5. Each Cy3-labeled methylated DNA from a cancer cell line was cohybridized with Cy5-labeled methylated DNA from normal lung. The percentages of hypermethylated loci in the cancer-cell DNA (Cy3:Cy5 > 10) were 3.2\% (H130, MINT23, H180, H156, MINT26, MINT19, H23), 2.3\% (H130, H23, MINT6, H139, MINT5), and 6.3\% (H130, MINT23, MINT26, H23, MINT6, H139, MINT5, MIN31, MINT12, MINT32, MINT24, MINT20, H152, H9) for EBC-1, 1-87, and LK79, respectively. These percentages are much higher than those described by a previous report (Yan et al. 2001). There are two reasons for this. The first is that our microarray included 29 DNA fragments with hypermethylated loci (MINT1-MINT32) in a colon cancer cell line. This indicates that common loci were hypermethylated in lung and colon cancer cells. The second reason is that only DNA fragments with methylated loci in cancer cells were fixed on our microarray. In the previous study (Yan et al. 2001), the origins of the fixed DNAs were not restricted to methylated loci. By choosing the methylated DNA library for the resource material of the microarray, we increased the percentage of DNA fragments derived from hypermethylated loci on the microarray. The loci that were hypermethylated in at least two cancer cell lines are listed in Fig. 2A. We picked up MINT26 for further 
A

$\begin{array}{lccccl} & \text { EBC-I } & 1-87 & \text { LK79 } & \begin{array}{l}\text { Genbank } \\ \text { Accession } \\ \text { No. }\end{array} & \begin{array}{l}\text { BLAST } \\ \text { Homology }\end{array} \\ \text { H130 } & - & - & - & \text { AB080358 } & \text { EST } \\ \text { H23 } & - & - & - & \text { AB080359 } & \text { Zic3 } \\ \text { MINT23 } & - & \ddots & - & \text { AF135523 } & \text { CSX } \\ \text { MINT26 } & - & - & - & \text { AF135526 } & \text { Promoter of LOC136006 } \\ \text { MINT6 } & & - & - & \text { AF135506 } & \text { None } \\ \text { H139 } & \bullet & - & - & \text { AB080360 } & \text { Meranocortin I receptor } \\ \text { MINT5 } & & - & - & \text { AF135505 } & \text { Human CpG clone }\end{array}$

B

C

$$
\begin{aligned}
& \text { Cy } 3: \text { С } 5 \geq 10 \\
& 5 \leqq \text { } 3: \text { С } 5<10
\end{aligned}
$$

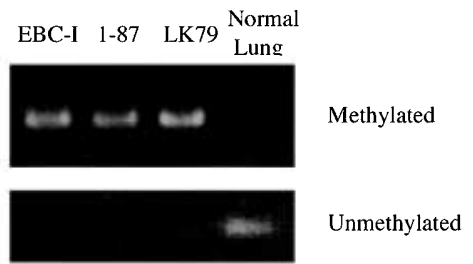

LOC136006 (MINT26)

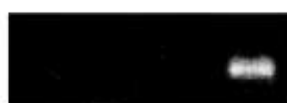

RT-PCR

G3PDH

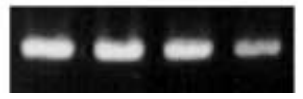

RT-PCR

Fig. 2. A Summary of the seven differentially methylated loci. B Methylation analysis of MINT26 (LOC136006). Methylation-specific PCR primer sequences that specifically recognized the methylated MIN26 sequence were TTTTAGATTAACGAGTTGGGCGAC and CGACTACATCAAAAACACGCCGA and those that recognized the unmethylated MIN26 sequence were TTGTGGAGTGATATAT TGGAAGTG and CATCAAAAACACACCAACCAATATCA. C Reverse transcriptase (RT)-PCR analysis of LOC136006 (MINT26) The primers used for LOC136006 were GGAGGAGTTCGTGGT AAGATG and GTGCTCTGGGAAGGATTACC. The primers used for G3PDH were ACCACAGTCCATGCCATCAC and TCCACCACCCTGTTGCTGTA

analysis because this locus is in the promoter of LOC136006 (GenBank accession number: XM_069647), which is similar to Neuralin 1. DNAs from each cancer cell line and from normal lung were treated with sodium bisulfite as described previously (Herman et al. 1996) and amplified by PCR. In three cancer cell lines, 150-bp fragments were amplified by primers that specifically recognized the methylated MIN26 sequence, thus indicating the methylation of this gene (Fig. 2B). In contrast, 61 -bp fragments were amplified by primers that specifically recognized the unmethylated MINT26 sequence in normal lung. Therefore, the hypermethylation of this gene was confirmed. To determine whether this hypermethylation was related to the expression of this gene, we performed reverse transcriptase (RT)-PCR analysis on these samples (Fig. 2C). No fragment was amplified from any of the three cancer cell lines, whereas a 198-bp fragment was amplified from normal lung, indicating a correlation between methylation and expression.

Very recently, a microarray-based technique for the detection of differences in methylation was developed (Yan et al. 2001). In that method, genomic DNA is cleaved with MseI followed by linker ligation. PCR amplification after cleavage with the methylation-sensitive restriction enzyme Bst UI results in the amplification of methylated MseI fragments. PCR products are labeled and hybridized to a microarray containing clones from a $\mathrm{CpG}$ island library. MseI fragments are not abundant in $\mathrm{CpG}$ islands, indicating that both non- $\mathrm{CpG}$ and $\mathrm{CpG}$ islands are used for hybridization. In our method, only $\mathrm{CpG}$ islands were amplified and used for hybridization, resulting in high sensitivity. In addition to this merit, our method has the great advantage of reducing the number of fixed clones on the microarray by restricting the resource to a methylated DNA library of the sample in which we want to detect hypermethylation. Moreover, our method would be useful for finding imprinted genes or tumor suppressor genes whose expression levels are too low to be found by an expression-based method.

Acknowledgments This work was supported by grants to I.H. from the Ministry of Education, Culture, Sports, Science, and Technology of Japan and the Human Frontier Science Program.

\section{References}

Antequera F, Boyes J, Bird A (1990) High levels of de novo methylation and altered chromatin structure at $\mathrm{CpG}$ islands in cell lines. Cell 62:503-514

Baylin SB, Herman JG, Graff JR, Vertino PM, Issa J-P (1997) Alteration in DNA methylation: a fundamental aspect of neoplasia. In: Vande Woude GF, Klein G (eds) Advances in cancer research vol. 72. Academic, San Diego, pp 141-196

Hatada I, Sugama T, Mukai T (1993) A new imprinted gene cloned by a methylation-sensitive genome scanning method. Nucleic Acids Res 21:5572-5582

Herman JG, Graff JR, Myohansen S, Nelkin BD, Baylin SB (1996) Methylation-specific PCR: a novel PCR assay for methylation status of CpG islands. Proc Natl Acad Sci U S A 93:98219826

Jones PA (1996) DNA methylation errors and cancer. Cancer Res 56:2463-2467

Li E, Beard C, Jaenisch R (1993) Role for DNA methylation in genomic imprinting. Nature 366:362-365

Ng H-H, Bird A (1999) DNA methylation and chromatin modification. Curr Opin Genet Dev 9:158-163

Pollack JR, Perou CM, Alizadeh AA, Eisen MB, Pergamenschikov A, Williams CF, Jeffrey SS, Botsein D, Brown PO (1999) Genome-wide analysis of DNA copy-number changes using cDNA microarrays. Nat Genet 23:41-46

Roberts CJ, Nelson B, Marton MJ, Stoughton R, Meyer MR, Bennett HA, He YD, Dai H, Walker WL, Hughes TR, Tyers M, Boone C, Friend SH (2000) Signaling and circuitry of multiple MAPK pathways revealed by a matrix of global gene expression profiles. Science 287:873-880

Schena M, Shalon D, Davis RW, Brown PO (1995) Quantitative monitoring of gene expression patterns with a complementary DNA microarray. Science 270:467-470

Singer-Sam J, Riggs AD (1993) X chromosome inactivation and DNA methylation. In: Jost JP, Saluz HP (eds) DNA methylation: molecular biology and biological significance. Birkhaeuser, Basel, pp 358384

Toyota M, Ho C, Ahuja N, Jair KW, Li Q, Ohe-Toyota M, Baylin SB, Issa JP (1999) Identification of differentially methylated sequences in colorectal cancer by methylated $\mathrm{CpG}$ island amplification. Cancer Res 59:2307-2312

Yan PS, Chen CM, Shi H, Rahmatpanah F, Wei SH, Caldwell CW, Huang TH (2001). Dissecting complex epigenetic alterations in breast cancer using CpG island microarrays. Cancer Res 61:83758380 